\title{
LOS RETOS DE LA EDUCACIÓN FORMAL ANTE UNA NUEVA Y CAMBIANTE NOCIÓN DE LO RURAL
}

\begin{abstract}
Resumen
El propósito de este artículo es discutir en torno a los retos que enfrenta la educación formal, en respuesta a los cambios ocurridos en el ámbito rural. Para cumplir con lo propuesto, en la primera parte, a manera de planteamiento del problema, se hace una aproximación al nuevo concepto de lo rural, contrastando lo actualmente dicho con posturas calificables como tradicionales. En la segunda se acentúa el tema de la pérdida de protagonismo de la agricultura como actividad sustentadora de las sociedades rurales, llamando, a través de ello, al reconocimiento de su carácter multidimensional. Retomando todo lo anterior, en la tercera parte se argumenta alrededor de los lineamientos que han de orientar la construcción de un nuevo modelo educativo que responda a las expectativas de las nuevas y actuales generaciones rurales, en un marco de apertura de fronteras. El artículo termina con algunas reflexiones acerca de la necesidad de diálogo y construcción conjunta entre los distintos actores relacionados y comprometidos con la educación dirigida al ámbito rural.
\end{abstract}

Palabras clave: Nueva ruralidad, educación rural, educación agrícola, sociedades rurales.

\section{THE CHALLENGES OF THE FORMAL EDUCATION BEFORE A NEW AND CHANGING NOTION OF THE RURAL THING}

\section{Abstract}

The purpose of this article is to discuss around the challenges that the formal education faces, in response to the changes happened in the rural realm. To expire with the proposed, in the first part, like exposition of the problem, an approach to the new concept of the rural realm is realized, confirming it with traditional positions. In the second part, the loss of de role of the azgriculture as a supportive activity of the rural societies is accentuated, calling to the recognition of his multidimensional character. Recapturing everything previous, in the third part, it is argued about the lineaments that have to orientate the construction of a new educational model, who answers to the expectations of the new and current rural generations in a contex of opening. The article ends with some reflections about the need of dialogue and combines construction between the different actors related and compromised with the rural education.

Key words: New rurality, rural education, agricultural education, rural societies.

\footnotetext{
*Profesor de la Universidad de Caldas, Manizales. E-mail: marlon.mendez@ucaldas.edu.co Texto recibido el 10 de febrero de 2005 y aprobado el 3 de mayo de 2005.
} 


\section{INTRODUCCIÓN}

Para quienes el campo es nuestro espacio de desenvolvimiento cotidiano, la preocupación por el devenir de la educación rural, constituye una constante. Experimentar y evidenciar los cambios acaecidos en el mundo rural, nos predispone a compartir lo encontrado con todos aquellos comprometidos o relacionados con la superación del conjunto de problemas estructurales que impiden a las sociedades rurales potenciar su desarrollo, reconociendo que la educación representa una de las principales respuestas a la problemática planteada, lo que viene a continuación puede ser interpretado como un llamado a la disertación y a la planeación colectiva. Ante las transformaciones sucedidas, la educación tradicionalmente ofertada no puede continuar inmóvil. Definitivamente, el reto está en motivar el movimiento, así como la lectura desde los más diversos planos, asuntos a los que apunta el siguiente artículo.

\section{La noción de lo rural}

Antes de dar paso a los retos de la educación formal en sí, es conveniente que nos ubiquemos en la

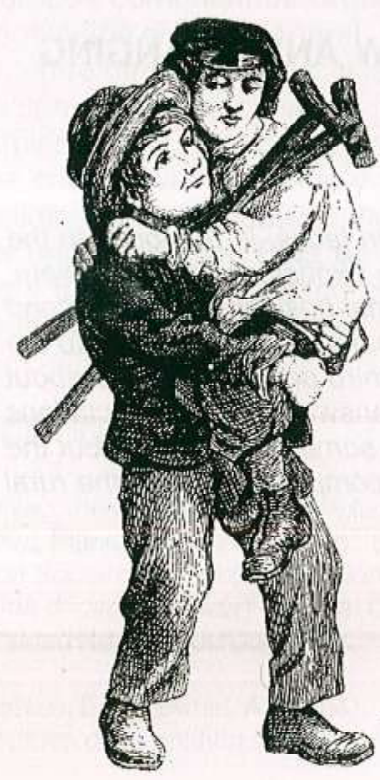

manera como ha sido y viene siendo interpretado el concepto de lo rural. Con este propósito, partiendo de lo expuesto por diversos actores, a continuación exploraremos la ruta de cambios sugerida.

Según Pickenhayn (1982:37), quien escribe sobre la década de los ochenta, el hábitat rural puede definirse a través de la enunciación resumida de sus características más singulares:

a) Es una forma generalizada de ocupación humana del espacio.

b) Se asocia a un género de vida de tipo alimentador.

c) Se liga específicamente a la explotación de recursos naturales.

d) Es autosuficiente y puede presentar fuertes superávit de producción si el entorno lo permite.

e) Se desarrolla con máxima extensión y mínima población (baja densidad de población humana).

f) Es muy vulnerable a los agentes físicos externos (inundaciones, sismos, desequilibrios ecológicos, etc.).

g) Refleja una estrecha asociación del hombre hacia su entorno.

Según Bejarano (1998:34), quien desde un tiempo más cercano evoca lo que él mismo reconoce como una visión tradicional de lo rural, éste corresponde a un orden social singularizado con las siguientes propiedades:

a) Local, autártico y cerrado.

b) Socialmente estructurado a partir de la propiedad, y

c) Correspondiente a la territorización de lo agrícola.

De acuerdo con Ramos y Romero (1993:83), autores que hacen énfasis en la visión actual, lo rural corresponde a una entidad socioeconómica en un espacio geográfico que funciona con cuatro componentes básicos:

a) Un territorio que funciona como fuente de recursos naturales y materias primas, receptor de re- siduos y soporte de actividades económicas.

b) Una población que, con base en cierto modelo cultural, practica actividades muy diversas de producción, consumo y relación social, formando un entramado socioeconómico complejo.

c) Un conjunto de asentamientos que se relacionan entre sí y con el exterior, mediante el intercambio de personas, mercancías, información, a través de canales de relación.

d) Un conjunto de instituciones públicas y privadas que vertebran $y$ articulan el funcionamiento del sistema, operando dentro de un marco jurídico determinado.

Siguiendo a Ceña (1993:52), quien comparte mucho de lo anteriormente expuesto, "lo rural es un conjunto de regiones y zonas con actividades diversas (agricultura, artesanía, industrias pequeñas y medianas, comercio, servicios) en las que se asientan pueblos, pequeñas ciudades y centros regionales, espacios naturales y cultivados".

Si hacemos una lectura comparativa de lo expuesto por los diferentes autores, encontramos que los cambios en la noción de lo rural apuntan a la superación del tradicional y acentuado sesgo agrícola. Si en contraposición a las dos primeras definiciones acogemos lo expuesto por las dos últimas, es fácil identificar que lo rural de ahora no se limita a lo agrícola.

Como introducción a este debate, Jiménez (1998:6) plantea que si hacemos el ejercicio de preguntar a la gente del común qué es lo rural, muy probablemente encontrariamos respuestas como las siguientes: Io rural es el campo, la agricultura, el mundo de los campesinos. Aquí lo rural es definido por asociación a aquellos elementos más visibles en el entorno: localización, actividad económica y actores sociales, en donde los términos campo, mundo campesino, agricultura y rural son usados como sinónimos, revelando, 


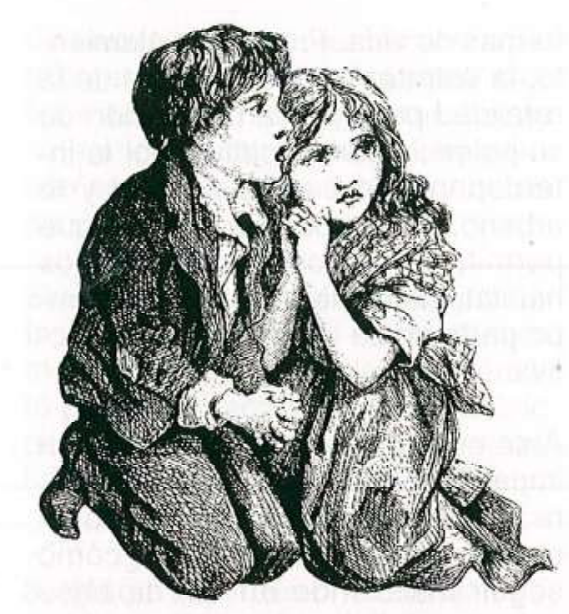

a través del lenguaje, la inseparabilidad percibida entre agricultura, ruralidad y sociedad. No obstante, la visión de un observador mucho más cauto y preciso, con seguridad va más allá de lo anteriormente señalado. Ante esta insistencia, al ubicarnos en el entorno rural es necesario reconocer la multiplicidad de actividades allí realizadas. Agricultura, comercio, servicios derivados de la producción agrícola, servicios que responden a las demandas sociales de la propia población rural (educación, salud, recreación, entre otras) y actividades industriales y artesanales hacen parte de la diversidad mencionada.

Por otro lado, como bien anotan los autores citados, el nuevo concepto reconoce que el espacio siempre está formado de flujos e interflujos. Siguiendo esta premisa, la noción de lo rural como un espacio local, autártico y cerrado sugiere ser reelaborada. La idea de movilidad exige prestar total atención a la trama de ires y venires suscitada en función de la vida cotidiana de los muchos y diversos actores rurales.

Asociado a lo anterior, y ubicándonos en el plano de su sustento empírico, podemos decir que por encima de cualquier categorización teórica, son los habitantes rurales quienes saben dónde empieza y dónde termina funcionalmente su espacio de desenvolvimiento cotidiano. Es- tos espacios son el resultado de diversos flujos, es decir, de la interacción social reconocida por los mismos habitantes en sus desplazamientos diarios, labores y ocupacionales habituales (Méndez, 2001: 70). En estos términos, aludiendo al proceso de desdibujamiento de fronteras, podemos decir que para un habitante del campo, su espacio cotidiano es tanto urbano como rural. De esta forma, para muchos habitantes del campo, la ciudad se ha convertido en un espacio de quehacer diario.

En estos términos, la noción tradicional, identificada con la idea de lo rural como un orden local y autártico, es superada por la visión territorial, entendido el territorio como una entidad compleja compuesta por poblaciones asentadas en diferentes espacios que se relacionan e interactúan entre sí y con el exterior, redefiniendo constantemente los límites en función de sus necesidades de funcionamiento. Lo rural entendido como un orden social fundamentado en la organización territorial, sugiere que cualquier intervención sobre su realidad se planee a partir del reconocimiento de las relaciones entretejidas entre los diferentes actores que constituyen un área determinada de influencia. Como menciona Plaza (1998:57),

las sociedades rurales no se caracterizan como habitualmente se definen, por estar insertas en una situación estática, sino más bien en situaciones dinámicas y cambiantes, tanto en el ámbito de las familias, como del ambiente socioeconómico local y nacional. Definitivamente, la identidad cultural y social no se logra por el aislamiento sino por la capacidad de interactuar con los contemporáneos y con los resultados de la historia.

En esta vía, lo rural, asociado a un género de vida de tipo alimentador, ampliamente sujeto a las actividades económicas primarias, pasa a ser ahora interpretado desde sus dimensiones no sólo económica y productiva, sino también geográfica, social, política, tecnológica, cultu- ral y ambiental. "La profundidad y significado de los cambios ocurridos ha conducido a muchos autores a designar a estos fenómenos como una nueva ruralidad, o más bien, nuevas ruralidades, destacando con esto último la diversidad de expresiones que se manifiestan en los diferentes espacios rurales" (Hernández y Thomas, 1999). Acotando lo anterior, los análisis e interpretaciones de las nuevas ruralidades han convencido a muchos autores de la necesidad de reconceptualizar dicha noción, ya que, para ellos, la categoría "rural" está obsoleta en el discurso de las ciencias sociales (Llambí, 1995).

Pero, si esto es así, ¿cómo, en la práctica, hacer frente al cambio? De esto nos ocuparemos a continuación.

\section{Desagriculturización de las sociedades rurales}

Sociedades rurales y agricultura han sido dos conceptos ampliamente ligados desde su origen. No obstante, la agricultura como actividad productiva que identifica y estructura todo un modelo de vida, si bien aún no ha dejado de ser el eje articulador de las culturas rurales, hoy día empieza a perder protagonismo. Desde la dimensión económica, el trabajo no agrícola ha ganado espacio en las sociedades rurales. Desde lo cultural, el avance de la modernidad sobre las sociedades tradicionales ha desatado un proceso de hibridación cultural, reflejado, en ocasiones, en las aspiraciones dẻ las nuevas generaciones de habitantes del campo.

Definitivamente, la ruralidad de base agrícola ha circulado en su historia por momentos de pérdida de función y ocupación, pero esos desajustes no eran sino manifestaciones normales de las formas vitales de ese hábitat socioeconómico específico. No obstante, como menciona Bericat (1993:48), 
a lo que se ha y está enfrentando la ruralidad del presente, es a un vaciado definitivo de la ruralidad por la acción de un intenso proceso de desagriculturización que, a modo de bomba de vacío, deja sin empleo, sin fuente de renta y sin sentido social a gran parte de los habitantes rurales. Ante esta situación, una muy importante cantidad de hombres, en breves lapsos de tiempo, son expulsados de una actividad que pensaban eterna, así como de un modo de ser sobre el que crecieron y se formaron indiferentes.

Por otro lado, las nuevas funciones sociales otorgadas a lo rural también han contribuido a que la agricultura ligada a la demanda alimentaria e industrial deje de ser la única actividad reconocida. Siguiendo a Ramos y Romero (1993:21), entre estas nuevas funciones se pueden destacar las siguientes:

a) Equilibrio territorial, contrarrestando los efectos de despoblamiento inducidos por el fenómeno de concentración urbana.

b) Equilibrio ecológico, en cuanto conservador de ecosistemas y procesos esenciales.

c) Producción de paisaje de calidad, abierto y natural, en contraposición al cerrado, artificial y crispado paisaje urbano.

d) Producción de recursos, como el agua limpia, recurso natural cada vez más escaso.

e) Soporte de actividades de esparcimiento y recreo al aire libre, ampliamente demandadas por una sociedad mayoritariamente urbana.

f) Sumidero de contaminación del aire, agua y suelo.

El planteamiento anterior sugiere que en atención a las nuevas funciones atribuidas al medio rural, nos encontramos ante el surgimiento de nuevas relaciones entre lo rural y el resto del territorio y la sociedad. De esta forma, la prestación de servicios en creciente demanda, como los ambientales y recreativos, constituye una alternativa de diversificación de la actividad rural, que posibilita y exige además la gestación de nuevos perfiles profesionales y ocupacionales en los habitantes del campo.

No obstante, es necesario considerar que la desagriculturización de lo rural no sólo atiende al ámbito económico o netamente funcional. Definitivamente hay que reconocer que aunque todo sistema social es constitutivamente conservador, todo sistema social está también en continuo cambio estructural. Para el caso de las sociedades rurales, el cambio en la estructura es también motivado por el continuo proceso de migración y retorno, por el relevo generacional de los miembros iniciales, por la incorporación de nuevos miembros que han interactuado fuera de la misma dinámica del medio, o por un proceso de autorreflexión acerca de la propia cotidianidad (Méndez, 2001:39). Es predecible que para un joven campesino, articulado de diferentes maneras a la dinámica urbana, y además sumido en un medio en donde lo rural es desvalorizado como opción de vida, la actividad agrícola tradicional resulte por fuera de sus intenciones futuras. Sin embargo, de su permanencia y de su vocación está dependiendo el devenir de los diferentes ámbitos rurales.

De acuerdo con Bericat (1993:51),

la ruralidad debe encontrar multitud de nuevos y pequeños poros de interacción e intercambio con el exterior, para así ir experimentando, innovando y consolidando nuevas estructuras socioeconómicas. Ningún sector o actividad concreto y específico mantendrá a la ruralidad en su conjunto, como anteriormente lo hiciera la agricultura. En todo caso, la estructura general debería ser básicamente heterogénea y diversa, como una especie de retícula neuronal activa. En este contexto, la nueva realidad ha de entender la lejanía o distancia física y social tan sólo como una mera circunstancia.

Siguiendo con lo expuesto por el mismo autor urbano, lo rural debe desagriculturizarse y plantear nuevas formas de producción, y nuevas formas de vida. Frente al aislamiento, la estrategia para el futuro de la ruralidad pasa por la ampliación de su potencia comunicativa, por la interdependencia entre lo rural y lo urbano, por la apertura reticular que permita la ósmosis entre los dos hábitat, manteniendo al mismo tiempo parte de su idiosincrasia respectiva.

Ante esta perspectiva, la educación impartida en el ámbito rural requiere ser ajustada. Pero, siendo conscientes de esta situación, ¿cómo seguir insistiendo en que la base estructural de la educación rural ha de ser la formación técnico-agrícola? Sin pretender demeritar la importancia de este componente para el sostenimiento del ámbito rural, es necesario sugerir que este tipo de formación debe mantener dicho carácter, es decir, el de componente que hace parte de un conjunto de disciplinas sobre las cuales los estudiantes han de desarrollar habilidad y competencia, a fin de poder desenvolverse con éxito ante la nueva y cambiante realidad rural. Definitivamente, como ya hemos señalado, lo rural no puede restringirse a lo agrícola.

No obstante, frente a la apertura de lo agrícola a otros ámbitos, es preciso considerar que esto no siempre implica rupturas abruptas y distantes. Hay que tener siempre presente que la actividad agrícola se complementa y es a su vez el complemento de otras; ésta está en su esencia ligada a la transformación industrial, a la prestación de servicios, a la producción, y mucho más ampliamente, a la generación de ingresos familiares como garantía de acceso campesino a los servicios sociales esenciales. Educación, salud, recreación, servicios institucionales, oferta de bienes básicos de consumo, son entre otros algunos de los principales servicios sociales demandados por las comunidades que habitan el campo. Ante esta situación, ¿por qué pensar que todo este tipo de bienes y servicios han de ser siempre suministrados des- 
de afuera y por actores ajenos a las mismas dinámicas del campo? Definitivamente, mientras lo rural se limite a lo agrícola, serán otros quienes suplan las necesidades rurales en cuestión.

Sin lugar a dudas, el reconocimiento de las situaciones hasta el momento planteadas sugiere el tránsito paulatino hacia un nuevo modelo de educación para la nueva ruralidad.

\section{Hacia un nuevo modelo educativo}

De acuerdo a Solís (2000),

la generación de nuevas visiones sobre formación de recursos humanos, acordes con la idea de que la juventud juegue un papel protagónico en el desarrollo rural, implica revisar crítica y profundamente los esquemas de educación formal y no formal que no han logrado objetivos claros de integración al medio al que los jóvenes pertenecen, y que han ayudado al desarraigo y crisis de la identidad cultural.

No obstante, ante esta lectura, es necesario considerar y revisar en qué términos se piensa la integración aludida.

Con mucha frecuencia, en contextos reales y comunes, los niños y jóvenes rurales asisten a una escuela urbana, a cargo de docentes urbanos, sometidos a programas curriculares genéricos que no reparan en las especificidades de origen de los educandos. Así, mientras en casa, como parte del proceso de socialización primaria, ellos viven el mundo rural, paralelamente, en la escuela, como parte del proceso de socialización secundaria, ellos incursionan en submundos urbanos, en donde su acervo social y cultural llega a ser negado o ignorado (Méndez, 2004:124). En definitiva, lo anterior es una muestra de desintegración. Sin embargo, es necesario considerar que la simple "agriculturización" o "ruralización" de los planes curriculares no es una medida

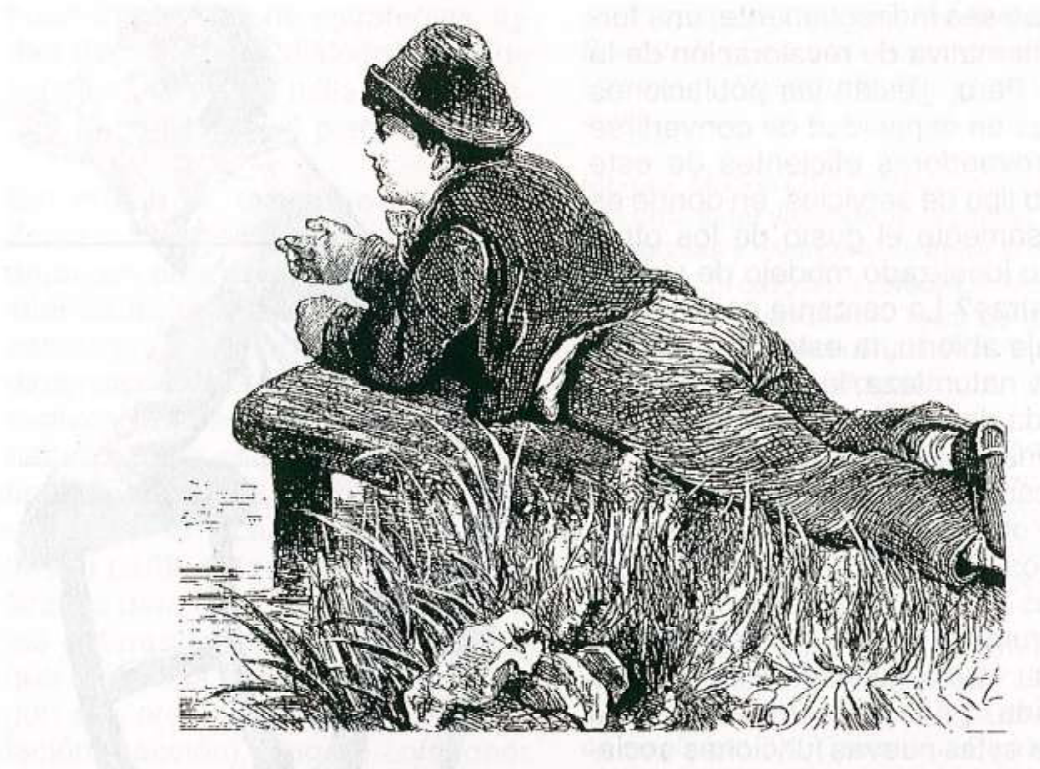

suficiente para hacer frente al problema. Pues, si nos ubicáramos en escenarios reales, ¿cómo insistir en la formación agrícola en aquellas zonas en donde la actividad productiva es vista por los mismos habitantes del campo como una opción ya poco viable?, o en otras palabras, si éste llegara a ser el caso, ¿por qué reforzar en la escuela la permanencia en un mundo sobrediagnosticado en crisis?

A estas alturas es importante considerar que para muchos jóvenes rurales el mundo que les es transmitido por sus padres no resulta del todo transparente. Puesto que no participaron en su formación, se les aparece como una realidad dada que, al igual que la naturaleza, es opaca al menos en algunas de sus partes. Siguiendo con esta idea, si nos ubicamos en el plano de lo vivido, ¿qué imagen ha de forjarse el niño o el joven acerca de su futuro agrícola y rural si a diario escucha a sus padres quejándose acerca de su propio presente?, o, ¿cómo insistir en retener a los jóvenes en el campo, cuando ser campesino es aun asumido como sinónimo de atraso e ignorancia?

Ante los problemas sugeridos, la revalorización de lo rural constituye una primera vía para seguir. Coincidiendo con lo expuesto por Hernández y Thomas (2000), "un paso inicial para reconstruir y fortalecer la identidad de las poblaciones rurales es el redescubrimiento y la revaIoración de su propia cultura local". Ante esta propuesta, los conocimientos y saberes populares, el lenguaje cotidiano, los significados que atribuyen a los elementos de su entorno, las creencias y las cosmovisiones, los sistemas tecnológicos tradicionales y adoptados, las tradiciones folclóricas, los estilos de aprendizaje y los patrones de interacción y de socialización son elementos por reconsiderar en un nuevo esquema de formación para la nueva ruralidad.

Al respecto, cabe señalar que el rescate de todo lo anterior, más que como una simple vuelta nostálgica al pasado, empieza a ser vista hoy como una medida estratégica de revaloración rural. Aunque para las nuevas generaciones, en cuanto referente identitario, el acervo cultural ha venido perdiendo importancia, actualmente, ante el afloramiento de actividades como el agro y el ecoturismo, éste ha vuelto a cobrar sentido. En este orden, la creciente demanda urbana de servicios ambientales y recreativos constituye, 
aunque sea indirectamente, una forma alternativa de revaloración de lo rural. Pero, ¿están las poblaciones rurales en capacidad de convertirse en proveedoras eficientes de este nuevo tipo de servicios, en donde es precisamente el gusto de los otros por su idealizado modelo de vida lo que atrae? La cercanía cotidiana al paisaje abierto, la estrecha relación con la naturaleza, la vida tranquila y alejada de la indeseable congestión citadina, la sencillez de la gente, su dedicación a actividades primarias, entre otros factores, constituyen elementos atrayentes. Pero, en situaciones en donde es la misma población rural la que se siente saturada por su forma histórica y tradicional de vida, ¿cómo asumir de buena forma estas nuevas funciones sociales?

Definitivamente, nuestras aseveraciones se sustentan en escenarios posibles. Sin embargo, quienes asumimos lo rural como objeto de estudio, estamos conscientes de su real expresión. Hoy día, para muchos sujetos rurales, tanto la agricultura como el mismo modelo rural de vida, han dejado de ser su primera opción. Como menciona Morett (2002:370), "si bien lo rural no es exclusivamente agrícola, lo cierto es que, en gran parte, lo rural se manifiesta en el conjunto de las actividades agropecuarias y especialmente en el trabajo de la tierra y el cultivo de plantas" (Morett, 2002: 370). Sin embargo, aquellas manifestaciones que se alejan de la media, más que descartarse como significativas, han de asumirse como expresiones de cambio y tránsito hacia la organización de un nuevo orden. Con frecuencia nuestra formación dentro del mismo ámbito agrícola nos impide observar más allá de nuestro campo. Es un hecho que la visión especializada fragmenta la aprehensión holística de la realidad. En esta tónica, si reducimos a los sujetos rurales a meros intérpretes del rol de productores agrícolas, dicha selectividad tipificante a la fija reduce nuestra mirada de conjunto.

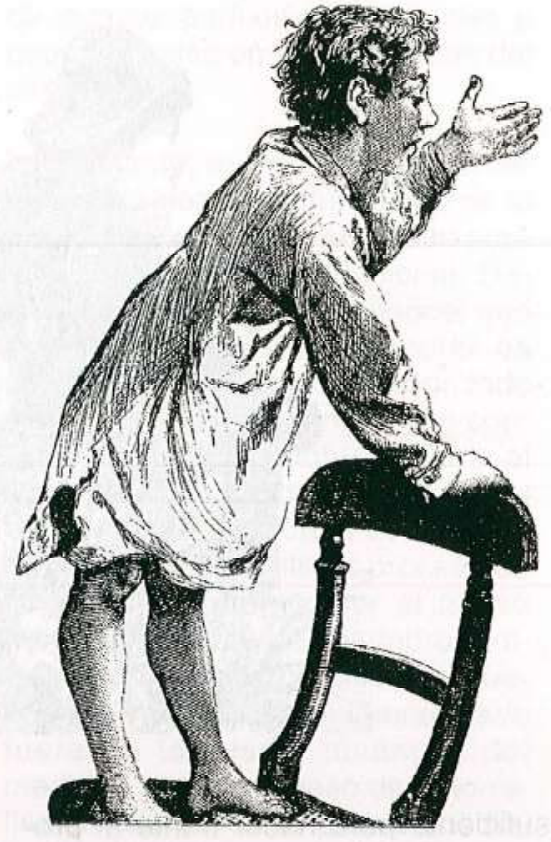

Si aceptamos con mesura lo anterior, nuevamente surge la siguiente inquietud: ¿Por qué insistir en reducir a los sujetos rurales a individuos inmersos y predeterminados hacia lo netamente agrícola? Coincidiendo con lo expuesto por Touraine (1997:174), es necesario reconocer que "el llamamiento a la libre construcción de la vida personal es el único principio universalista que no impone ninguna forma de organización social y prácticas culturales". Dicho principio asegura "respetar las libertades de cada quien, y por tanto implica el rechazo de la exclusión", sugiriendo, además, "que toda referencia a una identidad cultural se legitime mediante el recurso de la libertad y la igualdad de todos los individuos, y no por la apelación a un orden social, una tradición o las exigencias del orden público".

Situaciones como la anteriormente descrita plantean la necesidad de ver y pensar lo rural en un sentido amplio. Superar el tradicional sesgo agrícola es una exigencia prioritaria. En la práctica, en la medida en que la agricultura pierde su funcionalidad como actividad rural única y exclusiva, el orden tradicional e históricamente institucionalizado pierde legitimidad, por lo que transmitir su significado a las generaciones venideras resulta aún más complicado. Definitivamente, como ya se mencionó en los apartados anteriores, la actividad agrícola deja de ser la única opción de formación y especialización rúral. Un modelo de educación para la nueva ruralidad debe en esencia permitir explorar su multidimensionalidad, acción que ha de ser la base para la inducción, el descubrimiento y la diversificación vocacional.

En este punto es importante aclarar que la transmisión del significado de la institucionalidad agrícola ha sido hasta el momento el principal objeto de la educación rural tradicional. Pero, ante un entorno cambiante, en donde las nuevas generaciones conciben su propia condición existencial más allá de lo tradicionalmente impuesto, y en donde la interacción y el intercambio con el exterior están a la orden del día, ¿por qué insistir en igualar la educación rural a la mera formación para el ejercicio efectivo de actividades netamente agrícolas?

Si hoy al hablar de lo rural aludimos a su multidimensionalidad (acentuando que lo rural, además de agrícola y productivo, es también social, cultural, económico, político, ambiental e institucional), la educación formal con énfasis rural ha de estar en sintonía con lo planteado. Siguiendo esta propuesta, el paso por el sistema de educación formal debe permitir a los sujetos rurales explorar la totalidad de su dinámica de vida. Además de agricultores y productores pecuarios, del mismo ámbito rural han de surgir escritores, médicos, abogados, ingenieros, ecólogos, educadores, administradores..., conocedores y comprometidos con su entorno específico. Pues, ¿acaso las preocupaciones cotidianas de los pobladores rurales se restringen a aquello netamente relacionado con su rol específico de productores agrícolas? Atender a esta pregunta constituye el eje de análisis. 


\section{Reflexiones finales}

Asumir lo rural como una categoría dinámica implica replantear sus límites y elementos esenciales. Si adoptamos la idea de que la realidad no admite predeterminaciones, lo rural, como expresión de realidad, también está sujeto al cambio. Ante esta perspectiva, una labor prioritaria tanto para docentes en ejercicio y en formación, como para quienes tienen la responsabilidad de diseñar las políticas educativas, consiste en estar al tanto de los cambios acaecidos. Como tratamos de dejar en claro, liberarse de parámetros rígidos acerca de los sujetos rurales y sus predeterminaciones constituye una tarea apremiante, si lo que se quiere es reubicarse ante su realidad cotidiana. En este sentido, la multidimensionalidad del mundo rural demanda un educador capacitado para actuar de acuerdo con esta circunstancia. Desde esta perspectiva, superar el marcado sesgo agrícola-tecnicista constituye el principal desafío. Si lo rural no se limita a lo agrícola, la labor del docente inmerso en la dinámica rural ha de guardar correspondencia con lo expuesto, pues para nadie resulta extraño que para desenvolvernos con soltura en un escenario específico, una tarea mínima consiste en conocerlo bien.

Avanzar en la consolidación de esto último sugiere aprender a actuar en contexto, acción a la que se antepone aprender a reconocer dicho escenario específico de acción. Pero, ¿cómo lograrlo?

Una primera respuesta a este cuestionamiento básico consiste en fomentar un mayor acercamiento entre los diversos actores que en el campo asumimos el rol de educadores formales. En este sentido, el encuentro entre licenciados y pedagogos expertos, profesionales de las ciencias agropecuarias, sociólogos, antropólogos y otros comprometidos con la cuestión rural, constituye una de las rutas por seguir. Sin lugar a dudas, es en la cons- trucción conjunta de estrategias, todas derivadas del diálogo fluido de saberes, donde se halla la respuesta a la problemática planteada.

Sin embargo, tal como lo afirma Zemelman (1996:79), es necesario dejar en claro que "los enfoques interdisciplinarios, por mucho que se esfuercen por integrar las distintas dimensiones de la realidad, no resuelven la cuestión pertinente a la naturaleza de esa articulación". Definitivamente, no sólo se trata de componer la lectura de la realidad rural a partir de la información significativa para cada una de las distintas esferas (es decir, siguiendo lo que cada una de ellas requiere según sus propias líneas de interpretación y acción), sino de componer un cuadro con información que pueda leerse articuladamente.

\section{BIBLIOGRAFÍA}

Bejarano, Jesús (1998). "El concepto de lo rural: ¿Qué hay de nuevo?". En: Revista Nacional de Agricultura. No. 922-923, Colombia.

Bericat, Eduardo (1993). "La teoría del vacío rural". En: El desarrollo rural andaluz a las puertas del siglo XXI. Congresos y Jornadas, No. 32/93. Consejería de Agricultura y Pesca. Andalucía, España.

CEÑA, Felisa (1993). "El desarrollo rural en sentido amplio". En: El desarrollo rural andaluz a las puertas del siglo XXI. Congresos y Jornadas, No. 32/93. Consejería de Agricultura y Pesca. Andalucía, España.

Hernandez, Roberto y Thomas, Carlos (1999). "Educación, modernidad y desarrollo rural". En: Revista Enfoques educacionales. Volumen 2, Número 1, Departamento de Educación, Facultad de Ciencias Sociales, Universidad de Chile. Disponible en: http://csociales.uchile.cl/publicaciones/ enfoques/03/edu03.htm

JIMÉNEZ, Carlos (1998). "Lo rural y lo urbano: una reflexión en torno a su definición". En: Avances de investigación. Departamento de Sociologia Rural. Universidad Autónoma Chapingo, México.

LLAmBi, Luis (1995). "Globalización, ajuste estructural y nueva ruralidad". Ponencia central para el I Congreso Venezolano de Sociología y Economía Rural. Universidad Central de Venezuela. Maracay, Venezuela.

MÉNDEZ, Marlon (2001). "Vivir en el campo es como estar viviendo en la ciudad: convergencias y divergencias entre lo rural y lo urbano. El caso de la vereda Los Soches. Un estudio cualitativo". Tesis de grado. Maestría en Desarrollo Rural. Pontificia Universidad Javeriana, Bogotá.

. (2004). "Contradicción, complementariedad e hibridación en las relaciones entre lo rural y lo urbano". Tesis de grado. Maestria en Sociología Rural. Universidad Autónoma Chapingo, México.

MORETT, José (2002). "¿Qué es lo rural hoy día?". En: Memorias del Segundo Coloquio Internacional. El desarrollo rural en México en el siglo XXI. Cámara de Diputados, México.

Pickenhayn, Jorge (1982). Género de vida y hábitat rural y urbano. Facultad de Filosofía, Humanidades y Artes. Universidad Nacional de San Juan, Argentina.

PLAZA, Orlando (1998). Desarrollo rural. Enfoque y métodos alternativos. Pontificia Universidad Católica del Perú. Fondo Editorial, Perú.

Ramos, Eduardo y Romero, Juan. (1993). "La crisis del modelo de crecimiento y las nuevas funciones del mundo rural". En: EI desarrollo rural andaluz a las puertas del siglo XXI. Congresos y jornadas, No. 32/ 93. Consejería de Agricultura y Pesca. Andalucia, España.

SoLis, Clara (2001). "Juventud y desarrollo rural en América Latina y el Caribe". En: Foro electrónico: Jóvenes en la nueva ruralidad. Consulta interamericana sobre juventudes rurales. IICA-CIDER-BID-OIJCEPAL. Disponible en: $h$ ttp://www.ilo.org/ public/spanish/region/ampro/cinterfor/temas/youth/doc/not/libro180/index.htm

Touraine, Alain (1997). ¿Podremos vivir juntos? Iguales y diferentes. México: Fondo de Cultura Económica.

Zemelman, Hugo (1996). Problemas antropológicos y utópicos del conocimiento. México: El Colegio de México. 


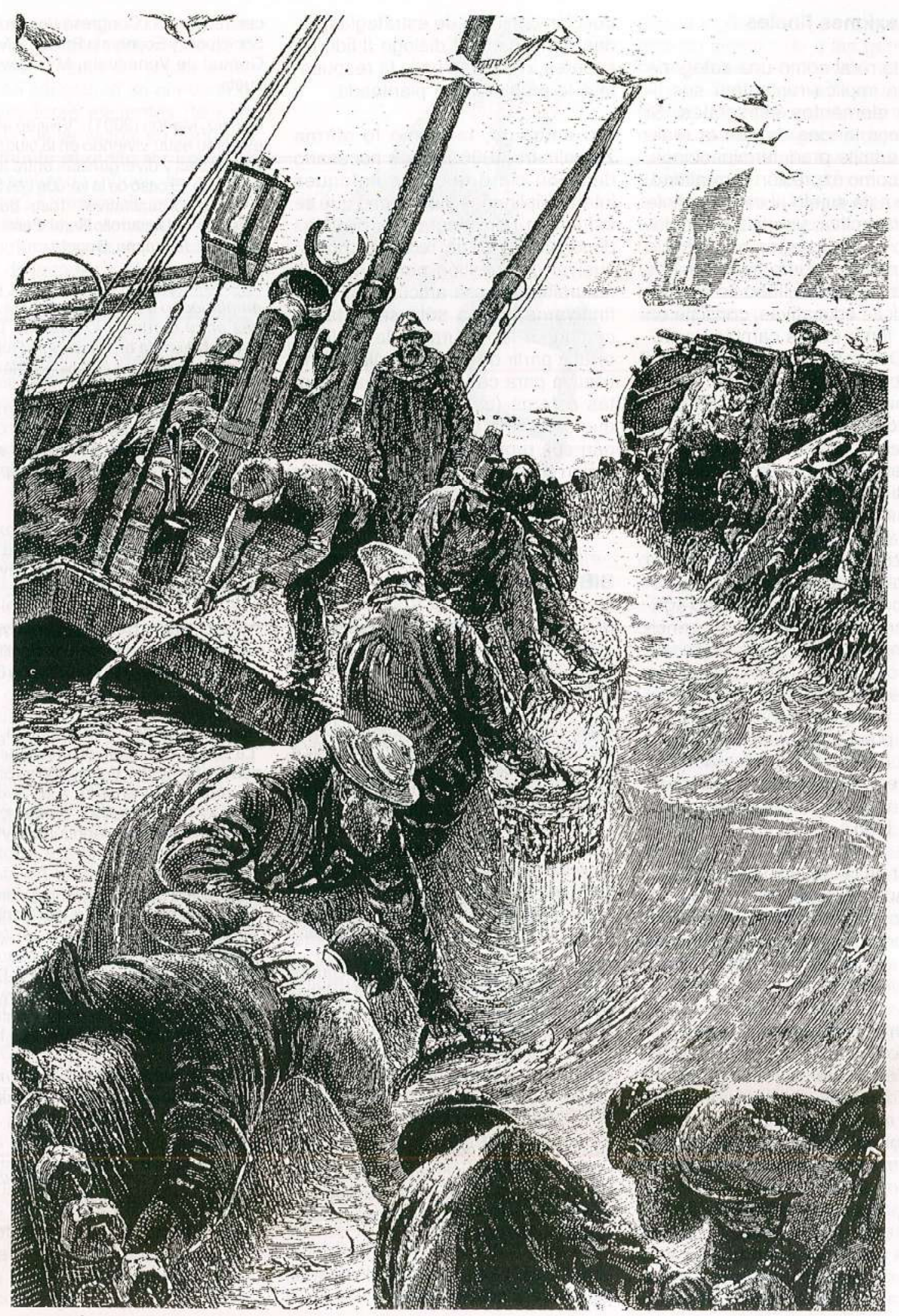

